\title{
IMP PCR primers detect single nucleotide polymorphisms for Anopheles gambiae species identification, Mopti and Savanna rDNA types, and resistance to dieldrin in Anopheles arabiensis Elien E Wilkins ${ }^{1,2}$, Paul I Howell1,2 and Mark Q Benedict*2
}

\author{
Address: ${ }^{1}$ Atlanta Research \& Education Foundation (AREF), Atlanta, GA, USA and ${ }^{2}$ Centers for Disease Control and Prevention (CDC), 4770 \\ Buford Hwy. MS F-42, Atlanta, GA 30341. Phone 770-488-4987, FAX 770-488-4258, USA \\ Email: Elien E Wilkins - EWilkins@cdc.gov; Paul I Howell - PHowell1@cdc.gov; Mark Q Benedict* - MBenedict@cdc.gov \\ * Corresponding author
}

Published: 19 December 2006

Malaria Journal 2006, 5:125 doi:10.1 I86/1475-2875-5-125
Received: 15 September 2006

Accepted: 19 December 2006

This article is available from: http://www.malariajournal.com/content/5/I/125

(C) 2006 Wilkins et al; licensee BioMed Central Ltd.

This is an Open Access article distributed under the terms of the Creative Commons Attribution License (http://creativecommons.org/licenses/by/2.0), which permits unrestricted use, distribution, and reproduction in any medium, provided the original work is properly cited.

\begin{abstract}
Background: Polymerase chain reactions to distinguish single-nucleotide polymorphisms are commonly used for mosquito identification and identifying insecticide resistance alleles. However, the existing methods used for primer design often result in analyses that are not robust or require additional steps.

Methods: Utilizing oligonucleotides that are unique in having an intentional mismatch to both templates three bases from the SNP at the 3-prime end, three new PCR assays that distinguish SNP targets using standard gel electrophoresis of undigested DNA fragments were developed and tested. These were applied to: (I) an alternative ribosomal DNA PCR assay to distinguish five members of the Anopheles gambiae complex; (2) detection of the Mopti and Savanna rDNA types; and (3) an assay to distinguish resistance to dieldrin $(R d l)$ alleles in Anopheles arabiensis.
\end{abstract}

Results: Reproducible specific amplification of the target alleles was observed in all three assays. The results were consistent with existing analyses but proved simpler and the results more distinct in our hands.

Conclusion: The simplicity and effectiveness of the method should be utilized in these and other PCR analyses to increase their specificity and simplicity. These results have the potential to be extended not only to mosquito analyses but also to parasite and human polymorphisms.

\section{Background}

Single nucleotide polymorphisms (SNPs) have been utilized as markers for species differentiation [1] and are implicated in insecticide resistance in many anopheline mosquitoes [2]. While various polymerase chain reaction (PCR) approaches to discriminate SNPs exist, specific primers for the wild-type and/or mutant alleles are often designed to perfectly match the sequence of one allele whereas the second varies only by matching the alterna- tive SNP sequence at the terminal 3' end. Therefore, it is critical that the biochemical specificity of the two primers is sufficient to determine the success of PCR amplification from a particular template. This PCR-specificity depends on two characteristics: the ability of any mismatch to prevent extension of the primer by the polymerase - many polymerases can synthesize template over a single terminal mismatch [3] - and the difference between the annealing temperature $\left(T_{m}\right)$ of the perfect and mismatched 
primer [4]. For both of these reasons, a single 3 ' mismatch has limited discrimination. In this report, intentional mismatches were used to increase the discrimination of PCR based primarily on the polymerase synthesis characteristic.

Three PCR analyses were created by the method described here:

(1) The Anopheles gambiae complex is comprised of six genetically and behaviourally distinct species that are morphologically almost identical [5]. Members of this complex have been identified as major vectors of human malaria parasites, and as many as four species may be sympatric. Several methods for identifying these species have been developed, such as gas chromatography of cuticular hydrocarbons [6], polytene chromosome arrangements (reviewed in [7]) and allozyme analyses [8]. However, none of these has obtained as widespread use as PCR amplification of the ribosomal DNA (rDNA). This has become the standard method for species discrimination since rDNA polymorphism detected by Southern hybridization [9] spurred development of a PCR assay [1]. While the Scott et al. PCR method is the most popular, non-specific bands and high rates of PCR amplification failure were observed in our hands.

(2) In addition to the cryptic species of the An. gambiae complex described above, karyotype analysis of the female ovarian chromosomes has revealed further subdivision into chromosomal forms called Forrest, Mopti (M) and Savanna (S) [7]. The observed frequencies of the inversions that define these types are correlated with different ecological zones suggesting that they may have an adaptive character. Because karyotype analysis is tedious and can only be performed on semi-gravid females, several alternative PCR-based methods have been developed. PCR amplification of the rDNA intergenic spacer IGS [1012] and internal transcribed spacers ITS1 and ITS2 [13] of An. gambiae s.s. have provided a molecular surrogate for karyotypes of Mopti and Savanna types in some but not all areas [13]. The novel method reported here was com- pared with the diagnostic PCR-RFLP method of Fanello [11] which amplifies a portion of the IGS followed by digestion of the products with $\mathrm{Hha}$ I to produce diagnostic fragments of either rDNA type.

(3) Resistance to dieldrin ( $R d l$ ) in An. gambiae s. l. is due to a single nucleotide mutation within the $\mathrm{M} 2$ transmembrane subunit of $\gamma$-aminobutyric acid (GABA) receptor [14]. In Anopheles arabiensis, resistance is conferred by an alanine to serine substitution within the $R d l$ locus. Resistance to dieldrin per se (a cyclodiene) is of little immediate concern since it has been banned from use in public health and agriculture. However, recently it has been shown that cross-resistance to the phenylpyrazole fipronil in Anopheles stephensi and An. gambiae was also due to the presence of an $R d l$ resistance allele $[15,16]$.

In this report, intentional mismatch primers - IMPs- a method previously utilized by Papp et al. [17] - were used to introduce mismatches at the third nucleotide from the $3^{\prime}$ end. This simple modification of intentionally adding a mismatch to the SNP-detection primers counter-intuitively increases the specificity of the primers, which is demonstrated here for three anopheline SNP detection analyses.

\section{Methods}

Mosquitoes

Mosquitoes were obtained from the Malaria Research and Reference Reagent Resource Center (MR4) holdings at the CDC in Atlanta, GA USA (Table 1). Larvae were reared at $27^{\circ} \mathrm{C}$ using a standard method [18] except that larva were fed Aquaricare ${ }^{\mathrm{TM}}$ Koi Floating Blend from the L2 stage to pupation.

\section{PCR}

Samples were prepared for PCR by the method of Rafferty et al. [19]. PCR products were observed by separation on $0.5 \times$ TBE agarose gels run in $0.5 \times$ TBE buffer at $12 \mathrm{v} / \mathrm{cm}$ and fragment sizes were estimated using a $1 \mathrm{~kb}$ ladder marker (Invitrogen ${ }^{\circledast}$ ). Thermal cycling for all analyses was performed in a Bio-Rad iCycler ${ }^{\circledast}$. Taq DNA polymerase

Table I: Mosquito stocks

\begin{tabular}{|c|c|c|c|c|c|c|}
\hline \multirow[b]{2}{*}{ Species } & \multirow[b]{2}{*}{ Stock } & \multicolumn{3}{|c|}{ Analysis } & \multirow[b]{2}{*}{ MR4 no. } & \multirow[b]{2}{*}{ Origin } \\
\hline & & rDNA & RdI & Species ID & & \\
\hline \multirow[t]{2}{*}{ An. gambiae s.s } & MOPTI & $x$ & & & MRA-763 & Mali \\
\hline & KISUMUI & $x$ & & $x$ & MRA-762 & Kenya \\
\hline An. merus & OPHANSI & & & $x$ & MRA-80I & South Africa \\
\hline An. quadriannulatus & SKUQUA & & & $x$ & MRA-76I & South Africa \\
\hline \multirow[t]{2}{*}{ An. arabiensis } & $\mathrm{KGB}$ & & $x$ & $x$ & MRA-339 & Zimbabwe \\
\hline & SENN & & $x$ & & MRA-764 & Sudan \\
\hline
\end{tabular}


and the manufacturer's (Promega ${ }^{\circledR}$ ) recommended buffer at $1 \times$ concentration was used for all reactions. PCR reactions consisted of $1 \mathrm{U}$ of $\mathrm{Taq}$ polymerase, $0.3 \mathrm{mM} \mathrm{MgCl}{ }_{2}$, all primers at $1 \mu \mathrm{M}$ except QD-3T at $2 \mu \mathrm{M}, 0.08 \mathrm{mM}$ dNTPs, and buffer in $25 \mu \mathrm{l}$ total volume. All primers used in these studies except those of Scott et al. are listed in Table 2 .

An. gambiae species identification PCR cycling consisted of melting at $95^{\circ} \mathrm{C}$ for $5 \mathrm{~min}$ followed by 30 cycles of $95^{\circ} \mathrm{C}$ for 30 seconds, $58^{\circ} \mathrm{C}$ for 30 seconds, and $72^{\circ} \mathrm{C}$ for 30 seconds, followed by one cycle of $72^{\circ} \mathrm{C}$ for $5 \mathrm{~min}$. Mopti and Savanna rDNA were analysed using PCRamplified rDNA and Hha I digests by the method of Fanello [11]. Hha I digests were performed overnight at $37^{\circ} \mathrm{C}$. The locations of novel primers were selected at SNP sites using published sequence data [Genbank: $\underline{\mathrm{AF} 470116}$ and $\underline{\mathrm{AF} 470112}$ ]. PCR thermal cycling for the IMP primers consisted of melting at $95^{\circ} \mathrm{C}$ for 5 min followed by 30 cycles of $95^{\circ} \mathrm{C}$ for 30 seconds, $54^{\circ} \mathrm{C}$ for 30 seconds, and $72^{\circ} \mathrm{C}$ for 30 seconds, followed by one cycle of $72^{\circ} \mathrm{C}$ for 5 $\min$.

An. arabiensis $R d l$-specific primers were designed to be used with the previously reported An. gambiae internal positive control primers RDLF and RDLR [14]. Thermal cycling consisted of melting at $95^{\circ} \mathrm{C}$ for 5 min followed by 30 amplification cycles of $95^{\circ} \mathrm{C}$ for 45 seconds, $53^{\circ} \mathrm{C}$ for 45 seconds, and $72^{\circ} \mathrm{C}$ for 45 seconds, followed by one cycle of $72^{\circ} \mathrm{C}$ for $10 \mathrm{~min}$. Heterozygous $\mathrm{F}_{1}$ individuals were produced for analysis by crossing KGB (homozygous susceptible) females to SENN (homozygous resistant) males en masse.

\section{Results and discussion}

The primer strategy for An. gambiae species identification was similar to that of Scott et al. [1]: one universal forward primer was used for all species in a cocktail with four species-specific reverse primers. However, neither the speciesspecific nor universal annealing sites were the same (Figure 1a). The species-specific DNA fragments that we obtain using the IMP primer set for An. gambiae s.l. species identification (Table 2) compare favorably to the products we obtain with the Scott et al. assay (Figure 2). While in the latter assay, non-specific artifact bands were observed, the IMP-protocol products are clear and consistent. Prior to developing these assays, primers were designed for the species identification except incorporating the deliberate mismatch at the penultimate base. These did not provide the desired level of specificity with the mismatch at this site. Additional primers were designed with a mismatch and the SNP in the middle in an attempt to thermodynamically alter the melting temperature sufficiently for discrimination. Neither of these approaches was successful.

In this study, only laboratory colonies of mosquitoes were tested for species ID, and validation on a larger scale as has been performed previously for Anopheles quadrimaculatus s.l. [20] will be necessary to confirm their utility. In order to ensure that the IMP primer sets would function correctly in strains other than those we analysed and for which sequence data was available, reported sequences were examined $[1,12,21-23]$ and no polymorphisms were found that would interfere with the success of the protocol.

An alternative to the Fanello protocol for analysis of the IGS was developed that is in principle like that of Favia et

Table 2: Primer sequences. Lower case nucleotide indicates the intentional mismatch, nucleotides in bold are located at site of SNP (where applicable), $\mathbf{F}$ and $\mathbf{R}$ indicate forward and reverse orientation.

\begin{tabular}{|c|c|c|c|}
\hline \multicolumn{3}{|c|}{ An. gambiae species ID } & \multirow[t]{2}{*}{ (5' to $\left.3^{\prime}\right)$ Fragment (size bp) } \\
\hline IMP-UN: & $\mathrm{F}$ & GCTGCGAGTTGTAGAGATGCG & \\
\hline & $\mathrm{R}$ & GCATGTCCACCAACGTAAAtCC & An. quadriannulatus (637) \\
\hline QD-3T & $\mathrm{R}$ & CAACССАСТСССTTGACGaTG & An. melas and merus (529) \\
\hline ME-3T & $\mathrm{R}$ & GCTTACTGGTTTGGTCGGCAtGT & An. gambiae (464) \\
\hline GA-3T AR-3T & $\mathrm{R}$ & GTGTTAAGTGTCCTTCTCCgTC & An. arabiensis $(388)$ \\
\hline \multicolumn{4}{|c|}{ Mopti/Savanna rDNA typing } \\
\hline M5 & $\mathrm{F}$ & CTTGGTCTGGAGACCGTTCCaTA & Mopti (426) \\
\hline M3 & $\mathrm{R}$ & GACACGTCAACTAAGTCAACACATtAC & \\
\hline S5 & $\mathrm{F}$ & GCCCCTTCCTCGATGGaGC & Savanna (335) \\
\hline S3 & $\mathrm{R}$ & CAACCGGCCCAAACGGcTT & \\
\hline \multicolumn{4}{|c|}{$R d l$ mutation assay } \\
\hline RDLF & $\mathrm{F}$ & AGTTTGTACGTTCGATGGGTTA & positive control (256) \\
\hline RDLR & $\mathrm{R}$ & CCAGCAGACTGGCAAATACC & \\
\hline AARDL & $\mathrm{F}$ & GCTACACCAGCACGTGaTT & dieldrin resistant (I58) \\
\hline RDLSS & R & CAAGACAGTAGTTACACCTAAaGC & dieldrin susceptible $(|2|)$ \\
\hline
\end{tabular}




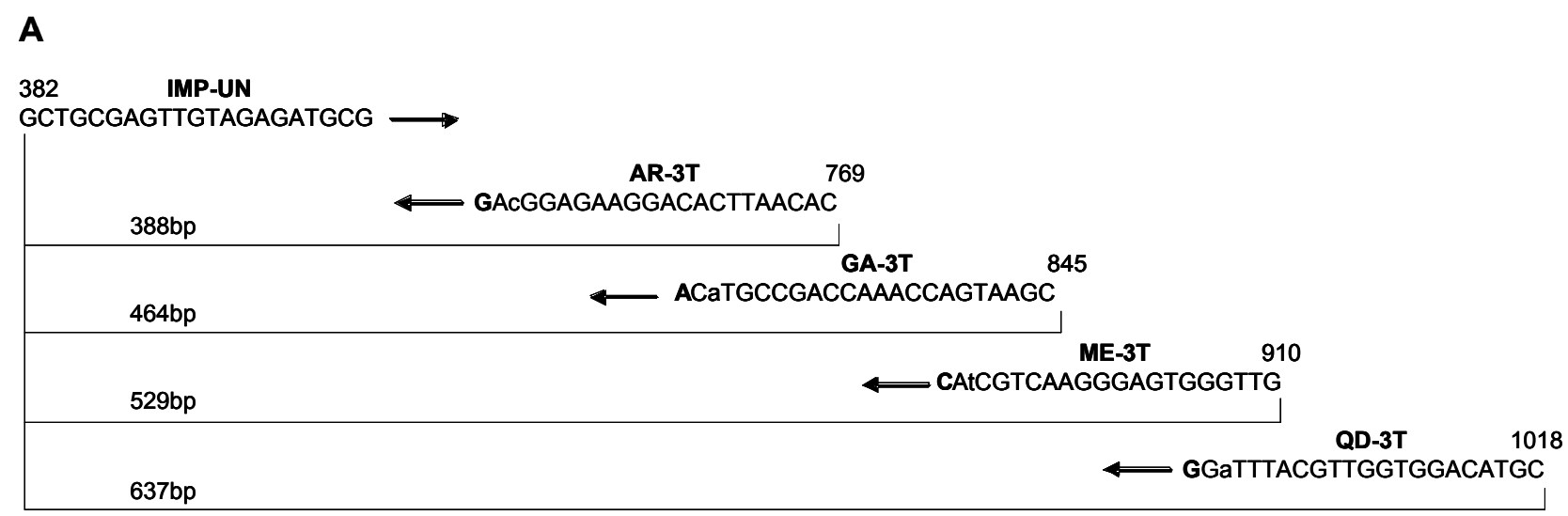

B

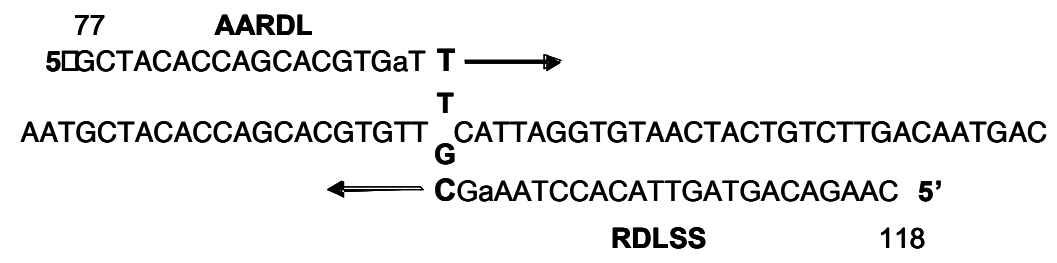

Figure I

Schematic alignment of IMP primers. (A) An. gambiae identification rDNA primers. The bp numbering is that of Scott et al. (1993). SNP sites are in bold, lower case nucleotides are intentional mismatches. The IMP-UN primer is shown in 5' to 3' orientation, whereas the reverse complement of all reverse primers are shown. (B) Alignment of Rdl primers. The bp numbering is as previously designated [Genbank: AY787486]. SNP sites are in bold, lower case nucleotides are intentional mismatches. The SNP sequence is $T$ or $G$ in the resistant and susceptible alleles respectively.

al. [12] in that PCR, but not restriction digestion, is required. In the Fanello analysis, the expected resulting fragments of the $M(367+23 \mathrm{bp})$ and $S(257+110+23$ bp) types include one only slightly smaller than the undigested 390 bp PCR product, therefore, high percentage agarose gels are used to distinguish products. The IMP primer design includes single base mismatches between the $\mathrm{M}$ and $\mathrm{S}$ rDNA in the target regions. They were designed to amplify distinct fragments of 426 or $335 \mathrm{bp}$ in the $\mathrm{M}$ and $\mathrm{S}$ forms respectively (Figure. 3 ). The results with these primers are consistent with those of the Fanello protocol and additional evidence of their consistency was obtained in a larger unrelated study.

The $R d l$ dieldrin resistance PCR assay contains two perfect-match primers (RDLF \& RDLR, [14]) that amplify the region containing the SNP and one forward and one reverse IMP primer that specifically bind the SNP found in An. arabiensis. The SNP site in An. arabiensis is located asymmetrically from the middle of the region between the
RDLF and RDLR primers so we were able to design a forward and a reverse primer at that site (Figure $1 \mathrm{~b}$ ), the forward primer being specific for the resistant form and the reverse specific for the susceptible form. The four primers are used in a cocktail together and are expected to yield a control band and a resistant or susceptible band in homozygotes depending on the templates. The result of using the four-primer cocktail with a heterozygote yielded three bands as expected (Figure 4).

The novel method, upon which these assays is based, is that all SNP-specific primers were designed to contain an intentional mismatch for both target alleles at the third nucleotide from the 3 ' end and with the terminal base falling on the site of the SNP [17]. These primers were tested over a wide range of annealing temperatures using a gradient cycler and were found to amplify their targets consistently and clearly over annealing temperatures of 50$65{ }^{\circ} \mathrm{C}$. This bodes favorably for reproducibility of the results obtained here on different machines. Successful 


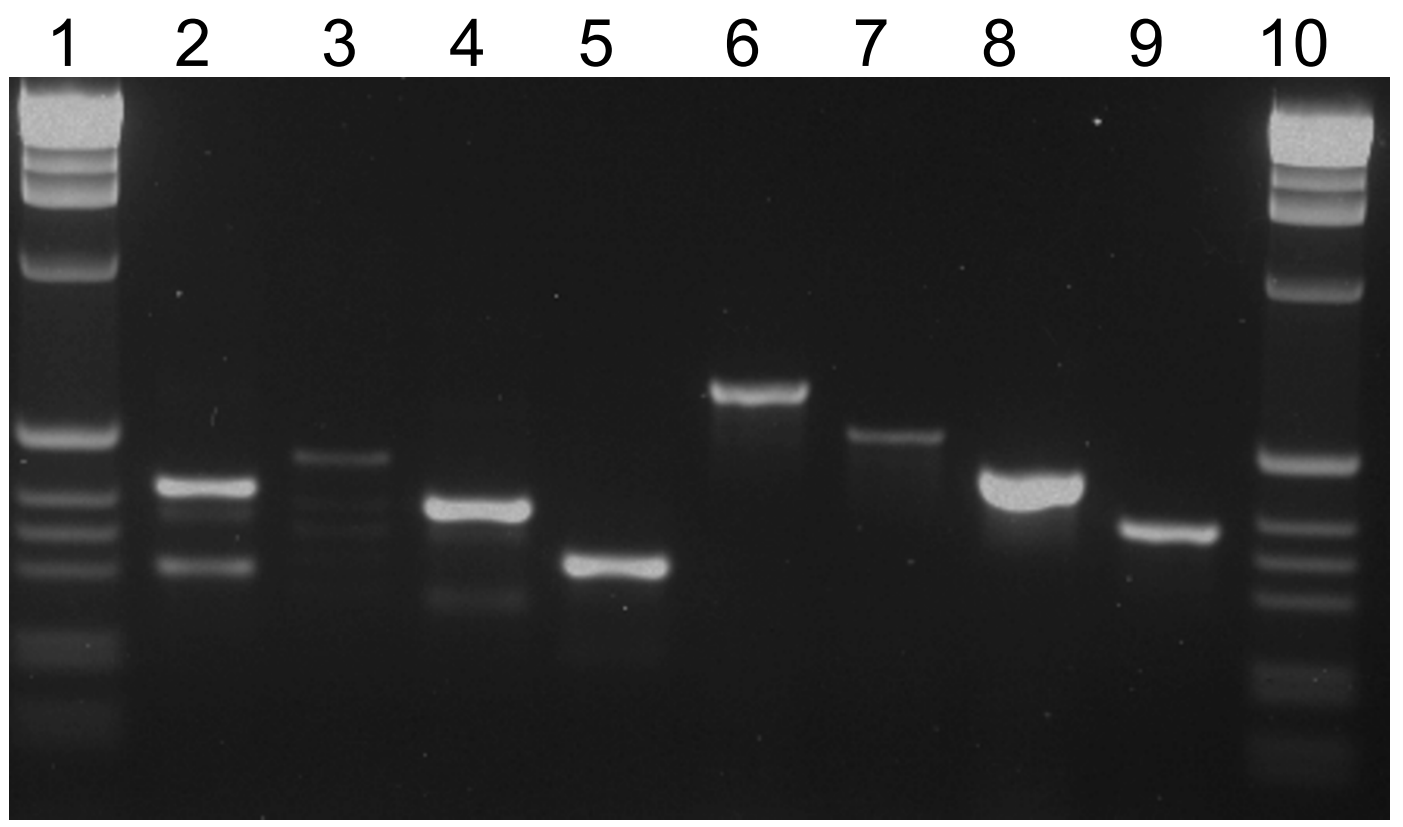

\section{Figure 2}

Gel electrophoresis of An. gambiae species identification comparing products produced by the method of Scott et al. and the IMP method presented in this paper. Lanes contain: $(I, 10)$ I kb ladder marker, (2-5) Scott et al. method, (2) An. quadriannulatus, (3) An. merus, (4) An. gambiae (KISUMUI), (5) An. arabiensis (KGB), (6-9) IMP method, (6) An. quadriannulatus, (7) An. merus, (8) An. gambiae (KISUMUI), and (9) An. arabiensis (KGB).

amplification over a wide range of temperatures also suggests that the primer design is successful not due to a thermodynamic change leading to a lower $\mathrm{T}_{\mathrm{m}}$ but rather due to the inability of a standard Taq polymerase to extend over a series with alternating mismatches at the 3 ' end.

\section{Conclusion}

Successful amplification using IMPs was achieved with all mosquito stages tested including larvae, pupae, and adult mosquitoes without extensive DNA purification. Therefore, these assays are useful for studies in the field where

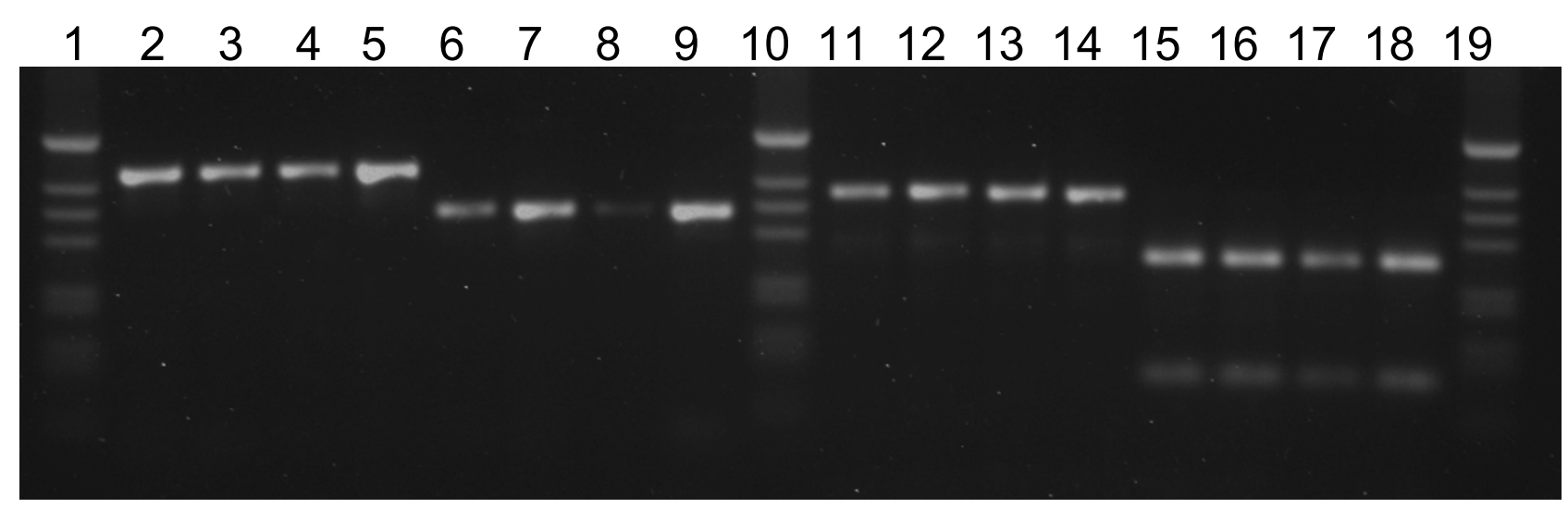

Figure 3

Gel electrophoresis of Mopti - Savanna rDNA assay. Lanes 2-5, II-I4 and 6-9, I5-I8 contain Mopti and Savanna PCR products respectively. Lanes 2-9 were performed using the IMP primers and reactions. Lanes II-I8 were performed by the method of Fanello. Lanes I, 10, and 19 contain I kb ladder marker. 


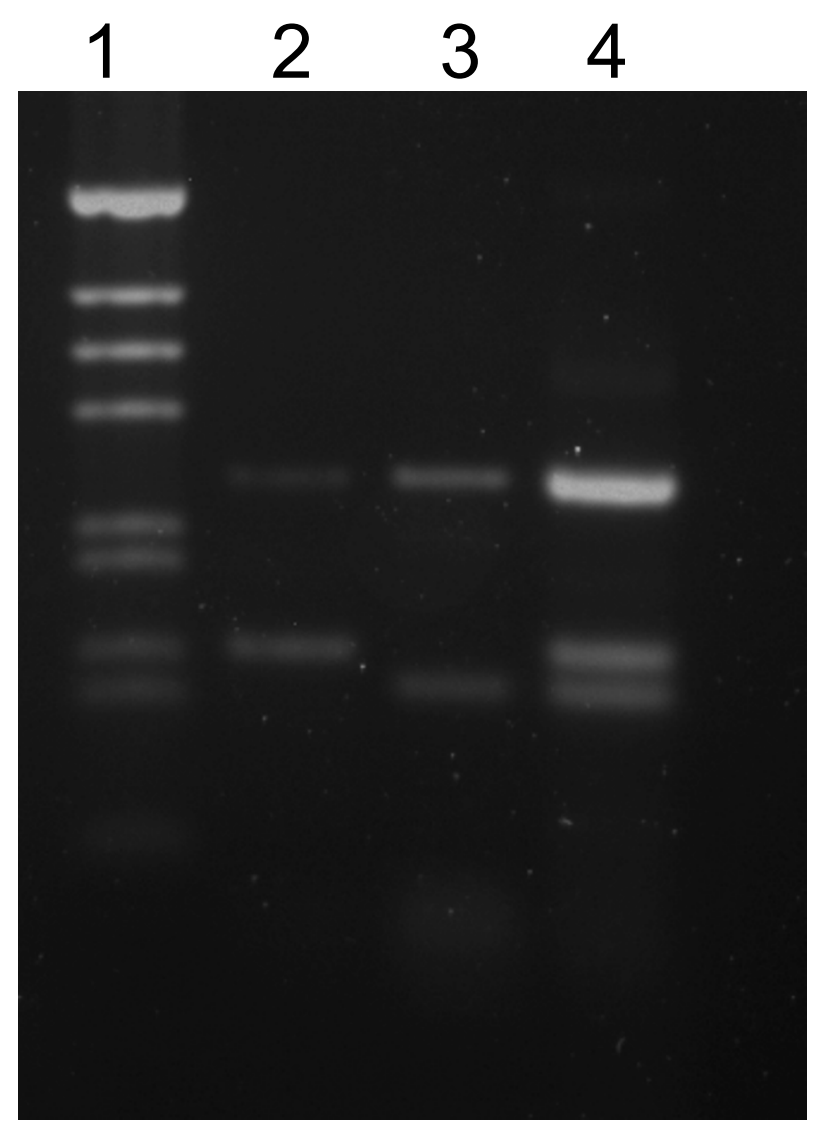

Figure 4

Gel electrophoresis of resistance to dieldrin assay. Lanes contain: (I) I kb ladder marker, (2) An. arabiensis dieldrin resistant (SENN), (3) An. arabiensis dieldrin susceptible (KGB), (4) An. arabiensis heterozygote from SENN $\times$ KGB.

DNA preparation is not possible or time-prohibitive. The ease of design, technical simplicity, high specificity, and sensitivity recommend these as improved specific assays and the general method as a means to produce assays for both multicopy and single-copy SNPs for laboratory and field analyses. There is no apparent reason that similar primer designs would not be useful for analysis of human and Plasmodium SNPs and any application in which rapid sensitive SNP discrimination is necessary.

\section{Authors' contributions}

EW carried out the primer design research, primer design and performed the first draft of the manuscript. PH participated in background research. Both EW and PH conducted molecular analysis, mosquito culture, and reviewed numerous revisions of the manuscript. $\mathrm{MB}$ participated in the design and coordination of the studies and helped to draft and performed the final review of the man- uscript. All authors read and approved the final manuscript.

\section{Acknowledgements}

We appreciate the American Type Culture Collection and the NIAIDfunded contract NOI-AI-85355 for their financial and moral support for the operation of the MR4 and their cooperation in developing and implementing the subcontract to the CDC Foundation that makes this research possible. Special thanks to all the donors of mosquito stocks without whose collegial generosity these experiments would not have been possible: Maureen Coetzee (KGB and SKUQUA), Vincent Corbel (KISUMUI), Mustafa Dukeen (SENN), Greg Lanzaro (MOPTI), and Rajendra Maharaj (OPHANSI). Thanks to Lynn Huynh for the careful editing and discussion of this manuscript.

\section{References}

I. Scott JA, Brogdon WG, Collins FH: Identification of single specimens of the Anopheles gambiae complex by the polymerase chain reaction. Am J Trop Med Hyg 1993, 49:520-529.

2. Hemingway J, Hawkes NJ, McCarroll L, Ranson H: The molecular basis of insecticide resistance in mosquitoes. Insect Biochem Mol Biol 2004, 34:653-665.

3. Zhang J, Li K, Liao D, Pardinas JR, Chen L, Zhang X: Different applications of polymerases with and without proofreading activity in single-nucleotide polymorphism analysis. Lab Invest 2003, 83: I|47-II54.

4. Guo Z, Liu Q, Smith LM: Enhanced discrimination of single nucleotide polymorphisms by artificial mismatch hybridization. Nat Biotechnol 1997, I 5:331-335.

5. Davidson G, Paterson HE, Coluzzi M, Mason GF, Micks DW: The Anopheles gambiae Complex. In Genetics of Insect Vectors of Disease Edited by: Wright JW, Pal R. Elsevier; 1967:21 I-250.

6. Carlson DA, Service MW: Identification of mosquitoes of Anopheles gambiae species complex A and B by analysis of cuticular components. Science 1980, 207:1089-I09I.

7. Coluzzi M, Sabatini A, Petrarca V, Di Deco MA: Chromosomal differentiation and adaptation to human environments in the Anopheles gambiae complex. Trans R Soc Trop Med Hyg 1979, 73:483-497.

8. Mahon RJ, Green CA, Hunt RH: Diagnostic allozymes for routine identification of adults of the Anopheles gambiae complex (Diptera, Culicidae). Bull Entomol Res 1976, 66:25-31.

9. Collins FH, Mendez MA, Rasmussen MO, Mehaffey PC, Besansky NJ, Finnerty V: A ribosomal RNA gene probe differentiates member species of the Anopheles gambiae complex. Am J Trop Med Hyg 1987, 37:37-4I.

10. McLain DK, Collins FH, Brandling-Bennett AD, Were JBO: Microgeographic variation in rDNA inergenic spacers of Anopheles gambiae in western Kenya. Heredity 1989, 62:257-264.

II. Fanello C, Santolamazza F, della Torre A: Simultaneous identification of species and molecular forms of Anopheles gambiae complex by PCR-RFLP. Med Vet Entomol 2002, I 6:46 I-464.

12. Favia G, Lanfrancotti A, Spanos L, Siden-Kiamos I, Louis C: Molecular characterization of ribosomal DNA polymorphisms discriminating among chromosomal forms of Anopheles gambiae s.s. Insect Mol Biol 200I, I0:19-23.

13. Gentile G, Slotman M, Ketmaier V, Powell JR, Caccone A: Attempts to molecularly distinguish cryptic taxa in Anopheles gambiae s.s. Insect Mol Biol 200I, I 0:25-32.

14. Du W, Awolola TS, Howell P, Koekemoer LL, Brooke BD, Benedict $M Q$, Coetzee M, Zheng L: Independent mutations in the Rd locus confer dieldrin resistance to Anopheles gambiae and An. arabiensis. Insect Mol Biol 2005, I4:179-183.

15. Brooke BD, Hunt RH, Coetzee M: Resistance to dieldrin + fipronil assorts with chromosome inversion $2 \mathrm{La}$ in the malaria vector Anopheles gambiae. Med Vet Entomol 2000, 14:190-194.

16. Kolaczinski J, Curtis C: Laboratory evaluation of fipronil, a phenylpyrazole insecticide, against adult Anopheles (Diptera: Culicidae) and investigation of its possible cross-resistance with dieldrin in Anopheles stephensi. Pest Manag Sci 200I, 57:4I-45. 
17. Papp A, Pinsonneault J, Cooke G, Sadee W: Single nucleotide polymorphism genotyping using allele-specific PCR and fluorescence melting curves. Biotechniques 2003, 34:1068-1072.

18. Benedict MQ: Care and maintenance of anopheline mosquito colonies. In The Molecular Biology of Insect Disease Vectors Edited by: Crampton JM, Beard CB, Louis C. New York: Chapman \& Hall; 1997:2-12.

19. Rafferty C, Campbell S, Wirtz R, Benedict M: Polymerase chain reaction-based identification and genotyping of Anopheles mosquitoes with a 96-pin bacterial replicator. Am J Trop Med Hyg 2002, 66:234-237.

20. Rutledge CR, Cornel AJ, Meek CL, Collins FH: Validation of a ribosomal DNA-polymerase chain reaction species diagnostic assay for the common malaria mosquito (Diptera:Culicidae) sibling species complex. J Med Entomol 1996, 33:952-954.

21. Gentile G, Della Torre A, Maegga B, Powell JR, Caccone A: Genetic differentiation in the African malaria vector, Anopheles gambiae s.s., and the problem of taxonomic status. Genetics 2002, 161:1561-1578.

22. Besansky NJ, Powell JR, Caccone A, Hamm DM, Scott JA, Collins FH: Molecular phylogeny of the Anopheles gambiae complex suggests genetic introgression between principal malaria vectors. Proc Natl Acad Sci USA 1994, 9 I:6885-6888.

23. Cornel AJ, Collins FH: PCR of the ribosomal DNA intergenic spacer regions as a method for identifying mosquitoes in the Anopheles gambiae complex. In Methods in Molecular Biology: Species Diagnostic Protocols: PCR and other nucleic acid methods Volume 50. Edited by: Clapp JP. Totowa NJ: Humana Press; 1996:32I-332.

Publish with Bio Med Central and every scientist can read your work free of charge

"BioMed Central will be the most significant development for disseminating the results of biomedical research in our lifetime. "

Sir Paul Nurse, Cancer Research UK

Your research papers will be:

- available free of charge to the entire biomedical community

- peer reviewed and published immediately upon acceptance

- cited in PubMed and archived on PubMed Central

- yours - you keep the copyright

Submit your manuscript here:

http://www.biomedcentral.com/info/publishing_adv.asp
BiolMedcentral 